
\title{
Reserarch Sulure \\ Evaluation and validation of technical procedure for foundry coke mechanical strength testing
}

Bartosz Mertas ( $\sim$ bmertas@ichpw.pl )

Instytut Chemicznej Przerobki Wegla https://orcid.org/0000-0003-0225-9481

Aleksander Sobolewski

Instytut Chemicznej Przerobki Wegla

Grzegorz Rozycki

Instytut Chemicznej Przerobki Wegla

Research

Keywords: foundry coke, coke strength, test method, statistical evaluation

Posted Date: May 11th, 2020

DOI: https://doi.org/10.21203/rs.3.rs-27296/v1

License: (1) This work is licensed under a Creative Commons Attribution 4.0 International License.

Read Full License 
Bartosz Mertas $^{1 *}$, Aleksander Sobolewski $^{1}$, Grzegorz Rozycki ${ }^{1}$

Evaluation and validation of technical procedure for foundry coke mechanical strength testing

1) Institute for Chemical Processing of Coal, 1 Zamkowa Str, 41-803 Zabrze, Poland

${ }^{*}$ corresponding author: bmertas@ichpw.pl

ORCID: 0000-0003-0225-9481, 0000-0003-2581-7212, 000-0001-5228-885X

Keywords: foundry coke, coke strength, Micum, statistical analysis

\begin{abstract}
Foundry coke is a special type of coke with lumps size usually bigger than $100 \mathrm{~mm}$. Therefore it is difficult to asses its physical properties representatively for whole lot. There exist international standards for coke sampling and testing strength index (usually Micum test). Nevertheless companies dealing with foundry coke notified problems with methodology of sampling and sample preparation for the test. Manual sampling according to ISO 18283 is very labour extensive and with connection with literally proceeding with ISO 566 gives nonrepresentative results for foundry coke $+100 \mathrm{~mm}$. For this reason on the basis of these standards there was evaluated procedure for coke sampling and testing strength indexes which is more practical for plant routine use and gives more reliable results in comparison to international standard. This article presents results of work aimed at checking usability of ISO standards provisions for foundry coke testing and evaluation and validation of simplified procedure.
\end{abstract}

Keywords: foundry coke, coke strength, test method, statistical evaluation

\title{
Declarations
}

Funding

Not applicable

Conflicts of interest/Competing interests

Not applicable

Availability of data and material

Not applicable

Code availability

Not applicable

\author{
Authors' contributions \\ Not applicable
}

Code availability

Not applicable 


\section{Introduction}

Poland is a substantial producer and exporter of the foundry coke. The coke quality requirements are determined in each contract. For foundry coke one of the most important parameters is mechanical strength usually expressed as Micum index $\mathrm{M}_{80}$. It gives information about strength of big pieces of coke and it is measured usually according to ISO 556 standard [1]. There are notified many times significant discrepancies between the results obtained in laboratories at the plant and at the coke buyers so there is need to asses results from carrying out tests strictly according to ISO standards for such type of material.

The strength of coke pieces depends a lot on fissures pattern in coke lumps. Fissures are generated due to stresses that appears during carbonisation in a coke oven and depends on different contraction behaviour in different layers of charge at different temperatures [2]. Depending on coke mean size there is also influence on coke fissures and further on coke strength [3].

For many plants realisation of sampling in automated manner is from the technological view impossible. ISO 18283 [4] gives guidelines for manual sampling of coal and coke. Nevertheless for foundry coke with lumps of $+100 \mathrm{~mm}$ is very difficult in use. In addition strength test according to ISO 556 requires sieve analysis of general sample to prepare test portions. What is also important to point out is the fact that ISO 556 does not give information about repeatability, reproducibility nor uncertainty for obtained results for Micum $\mathrm{M}_{80}$. These were incentives for realization of presented work.

The article presents results of work aimed at:

- challenging the rightness of ISO 18283 [4] and ISO 566 [1] standards provisions application to the foundry coke of $+100 \mathrm{~mm}$ grain size on the basis of tests results,

- developing a tool for quality assessment for foundry coke of $+100 \mathrm{~mm}$ grain size of indices analogous to $\mathrm{M}_{80}, \mathrm{M}_{40}$ and $\mathrm{M}_{10}$ indexes.

The study was carried out in the following stages:

- the analysis of strength indexes determination for the foundry coke,

- experimental assessment of strength indexes determination for the foundry coke,

- introduction of amendments to ISO procedures for determination of foundry coke strength,

- $\quad$ statistical evaluation of the obtained results,

- conclusions and recommendations.

\section{Experimental}

The experimental assessment of foundry coke strength index determination was carried out according to following plan:

I stage - evaluation of existing test standards/procedures:

1. sampling of foundry coke according to:

- ISO 18283:2006 standard [4],

- coke producer own procedure,

2. performing Micum $\mathrm{M}_{80}, \mathrm{M}_{40}$ and $\mathrm{M}_{10}$ indexes determinations according to the ISO 556 [1],

3. statistical evaluation of results.

II stage - evaluation of new test procedure

1. on the basis of ISO standards $[1,4]$ preparation of new procedure for coke sampling and strength testing,

2. sampling of foundry coke and performing strength indexes determinations according to new procedure,

3. statistical evaluation of results.

For the first stage of work in accordance with provisions of the standard ISO 18283, the coke increments were sampled manually from a stopped conveyor belt and the combined sample had a mass of about $1000 \mathrm{~kg}$, which is consistent with the data included in Table 4 of ISO 18283 standard, informing about a minimum mass of sample for large pieces. The mass of each increment (according to Table 2 of the standard [4]) was more than $9 \mathrm{~kg}$. It was agreed that the amount of loaded coke during four days on the day-shift would be a lot and the amount of coke loaded during a single day-shift would be a sub-lot. This implied that according to standard minimum 31 increments should be taken per each sub-lot. During tests 33 - 35 increments were taken per each sub-lot.

Each gross sample taken from a sub-lot was subject to the sieve analysis, to determine fractions of individual size classes: > $250 \mathrm{~mm} ; 250-200 \mathrm{~mm} ; 200-150 \mathrm{~mm} ; 150-120 \mathrm{~mm} ; 120-100 \mathrm{~mm} ;<100 \mathrm{~mm}$. Because of the $>$ $250 \mathrm{~mm}$ size fraction content in the sub-lot at the amount smaller than the mass of a single coke lump, this fraction was not included in the test sample.

On the basis of obtained results of grain analysis, for each sub-lot 5 samples of $50 \pm 5 \mathrm{~kg}$ were composed for a drum test, of particle composition corresponding to the gross sample. The drum tests were carried out in accordance with the ISO 556 standard.

\section{Evaluation of existing test standards/procedures results}

For the first stage of work there were introduced two sampling methods described in Table 1. 
Table 1

Comparison of the applied methodologies of foundry coke $+100 \mathrm{~mm}$ sampling

\begin{tabular}{|c|c|c|}
\hline & ISO $18283[4]$ & producer \\
\hline Sub-lot & single shift & single shift \\
\hline Sampling location & stopped conveyor belt & running conveyor belt \\
\hline Sampling area & $\begin{array}{l}\text { min. } 3 \text { times higher than upper nominal } \\
\text { grain size }\end{array}$ & accessible place for sampling person \\
\hline Sampling frequency & min 31 samples for lot & $\begin{array}{l}\text { undetermined, sufficient for sampling } \\
\text { suitable amount of general sample of } \\
\text { coke per shift }\end{array}$ \\
\hline Weight of the increment & $>9 \mathrm{~kg}$ & individual piece \\
\hline $\begin{array}{l}\text { Placing location of the } \\
\text { increments }\end{array}$ & empty clean area & $\begin{array}{l}2 \text { steel barrels of }>200 \text { litres capacity, } \\
\text { individual piece into the next barrel }\end{array}$ \\
\hline $\begin{array}{l}\text { Weight of the general } \\
\text { sample }\end{array}$ & $\min 975 \mathrm{~kg}$ & $\sim 120 \mathrm{~kg}$ \\
\hline $\begin{array}{l}\text { Method of averaging the } \\
\text { general sample }\end{array}$ & coning and mixing & $\begin{array}{l}1 \text { barrel }(\sim 60 \mathrm{~kg}) \text { constitutes a sample } \\
\text { for testing }\end{array}$ \\
\hline Sample size distribution & results of sieve analysis & $\begin{array}{l}>100 \mathrm{~mm} \text { (subjectively chosen } \\
\text { individual pieces) }\end{array}$ \\
\hline
\end{tabular}

Fig. 1 present results of $\mathrm{M}_{80}, \mathrm{M}_{40}$ and $\mathrm{M}_{10}$ indexes determinations made for four sub-lots. Each sub-lot corresponded to a sample from each day of tests and consist of five individual strength tests. There are presented also standard deviation ranges in the form of error bars. Significant differences between mean Micum tests results may be noticed.

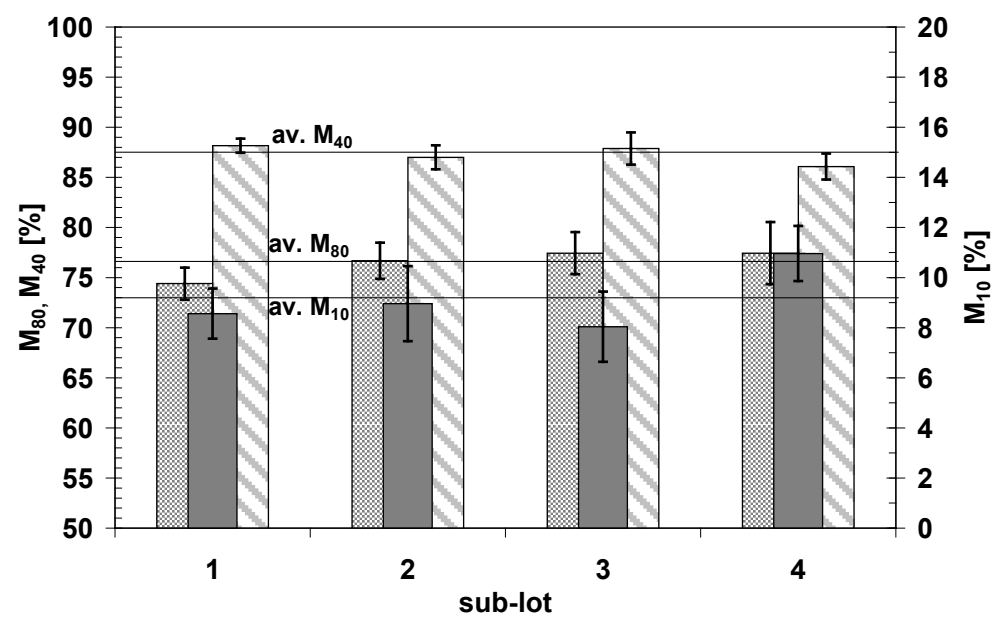

Fig. 1. Results of $\mathrm{M}_{80}, \mathrm{M}_{40}$ and $\mathrm{M}_{10}$ index

For each sub-lot the mean values, ranges, standard deviations of repeatability and repeatability limits at $95 \%$ confidence level for $\mathrm{M}_{80}, \mathrm{M}_{40}$ and $\mathrm{M}_{10}$ indexes have been determined based on the results of tests and are presented in Table 2.

Table 2.

Mean value $\bar{x}$, range, repeatability deviation $\mathrm{s}_{\mathrm{r}}$ and repeatability limit $\mathrm{r}$

\begin{tabular}{|c|c|c|c|c|}
\cline { 2 - 5 } \multicolumn{1}{c|}{} & $\overline{\mathrm{X}}$ & Range & $\mathrm{s}_{\mathrm{r}}$ & $\mathrm{r}(\alpha=95 \%)$ \\
\hline $\mathrm{M}_{80}$ & $74,4-77,4$ & $4,0-7,0$ & $1,64-3,08$ & $3,3-6,2$ (av. 4,3) \\
\hline $\mathrm{M}_{40}$ & $86,1-88,2$ & $1,6-4,0$ & $0,73-1,62$ & $1,5-3,2$ (av. 2,4) \\
\hline $\mathrm{M}_{10}$ & $8,0-10,9$ & $2,4-3,4$ & $0,96-1,48$ & $1,9-3,0$ (av. 2,5) \\
\hline
\end{tabular}

The arithmetic mean $\overline{\mathrm{x}}$ describes a general level of the determined index value (for $\mathrm{M}_{80}, \mathrm{M}_{40}$ and $\mathrm{M}_{10}$ ) in the whole population of results in the sub-lot. The range between results describes the difference between the maximum and the minimum value, while the standard deviation of repeatability $\mathrm{s}_{\mathrm{r}}$ describes the difference between 
a single result of measurement and the mean value in individual sub-lots. The lower values are reached by the standard deviation and the range, the higher is the accuracy and precision of performed measurements.

The repeatability limit $\mathrm{r}$ is the index value, which with $95 \%$ probability cannot be exceeded by the absolute difference between two parallel measurement results in individual sub-lots. It is calculated on the basis of the standard deviation of repeatability and appropriate $t$ coefficient (consistent with t-Student distribution), depending on the number of repetitions.

The determined values of ranges, of standard deviation of repeatability $\mathrm{s}_{\mathrm{r}}$ and of repeatability limits $\mathrm{r}$ for $\mathrm{M}_{40}$ and $\mathrm{M}_{10}$ indexes in all sub-lots are on a comparable level, but lower than in the case of $\mathrm{M}_{80}$ index. The highest value of deviation or repeatability limit for $\mathrm{M}_{40}$ and $\mathrm{M}_{10}$ is at the same time the lowest value for the $\mathrm{M}_{80}$ index.

One of the reasons of obtaining poor repeatability of results is the fact that the coke lumps of $+100 \mathrm{~mm}$ sizes are more diversified in terms of quality. The sample prepared for the Micum test contains coke lumps of varying sizes. To obtain appropriate mass of the sample, the number of coke lumps is 5-10 times smaller than in the case of coke of $+40 \mathrm{~mm}$ size. Therefore they do not characterise well the whole population (are less representative) and because of that it is difficult to obtain repeatable results of the test.

The ISO 556 standard, in accordance with which the mechanical strength tests were performed, presents a table (section 8.1.1) with determined repeatability limits depending on the number of repetitions - values for $\mathrm{M}_{40}$ from 3.0 to 4.0 and for $\mathrm{M}_{10}$ from 1.0 to 1.3. These values definitely differ from these tests results were these values are comparable. The repeatability limits for the $\mathrm{M}_{40}$ index fall within the range presented in the standard, while for the $\mathrm{M}_{10}$ index they definitely exceed this range. In the case of $\mathrm{M}_{80}$ index the values cannot be compared, because the standard does not provide such figures.

It is necessary to draw attention here to the fact that in the article discussed the number of repetitions is five, while in the standard the maximum number of repetitions, for which the repeatability was determined, is four. To compare properly the repeatability limits obtained in the study versus the number of repetitions, with the values given in the ISO 556 standard, the repeatability limits were determined for 2, 3 and 4 repetitions, respectively. The next results were chosen in such a way that the standard deviation of repeatability, and hence the repeatability limit, was maximum. Table 3 presents the calculated values of parameters in individual sub-lots for $\mathrm{M}_{80}, \mathrm{M}_{40}$ and $\mathrm{M}_{10}$ indexes.

Table 3

Repeatability limit $\mathrm{r}$ versus the number of repetitions

\begin{tabular}{|c|c|c|c|c|}
\cline { 2 - 5 } & \multirow{2}{*}{ results } & \multicolumn{3}{|c|}{$\begin{array}{c}\text { Repeatability limit r versus the num }(\alpha=95 \%) \\
\text { number of repetitions }\end{array}$} \\
\cline { 2 - 5 } & & 2 & 3 & 4 \\
\cline { 2 - 5 } & present test & $5,7-9,9$ & $4,4-8,0$ & $3,8-7,1$ \\
\cline { 2 - 5 } $\mathrm{M}_{80}$ & acc. ISO 556 & \multicolumn{3}{|c|}{ not stated } \\
\hline \multirow{2}{*}{$\mathrm{M}_{40}$} & present test & $2,3-5,7$ & $1,8-4,3$ & $1,6-3,7$ \\
\cline { 2 - 5 } & acc. ISO 556 & $\mathbf{3 , 0}$ & $\mathbf{3 , 6}$ & $\mathbf{4 , 0}$ \\
\hline \multirow{2}{*}{$\mathrm{M}_{10}$} & present test & $3,4-4,8$ & $2,6-3,8$ & $2,2-3,3$ \\
\cline { 2 - 5 } & acc. ISO 556 & $\mathbf{1 , 0}$ & $\mathbf{1 , 2}$ & $\mathbf{1 , 3}$ \\
\hline
\end{tabular}

Table 3 presents also the repeatability ranges for strength indexes in accordance with section 8.1 .1 of ISO 556 standard. When comparing the repeatability limits calculated in our study for the $\mathrm{M}_{80}$ index with limits presented in the standard it is possible to state that in the case of 4 repetitions these values fall in the standard ranges. In the case of 2 repetitions the repeatability limits exceed the standard limit values, which proves a difficulty in obtaining repeatable results.

The calculated repeatability for the $\mathrm{M}_{10}$ index is close to the repeatability determined for the $\mathrm{M}_{40}$ index. Comparing them with the values given in the ISO 556 standard it is clear that the determined repeatability significantly exceeds the standard values.

In the case of $\mathrm{M}_{80}$ index such comparison cannot be made, because the standard does not present the repeatability limits. However, based on Table 2 it is possible to notice that the value of repeatability for the $\mathrm{M}_{80}$ index is nearly twice higher than the repeatability value for $\mathrm{M}_{40}$ and $\mathrm{M}_{10}$.

On the basis of determined values of $\mathrm{M}_{80}, \mathrm{M}_{40}$ and $\mathrm{M}_{10}$ indexes the repeatability was calculated depending on the number of repetitions. The procedure of repeatability determination was based on the assumption that the absolute value of the difference between two results cannot exceed the standard deviation of repeatability, increased by an appropriate coefficient of critical range $f(n)$. This result is tabularised and depends on the number of repeated measurements. The final value of repeatability has been determined as the mean value of limits calculated for each sub-lot. Table 4 presents the obtained repeatability for $\mathrm{M}_{80}, \mathrm{M}_{40}$ and $\mathrm{M}_{10}$ indexes versus the number of repetitions.

Table 4

Repeatability for Micum strength $\mathrm{M}_{80}, \mathrm{M}_{40}$ and $\mathrm{M}_{10}$ versus the number of repetitions

\begin{tabular}{|c|c|c|c|} 
Number of repetitions & $\mathrm{M}_{80}$ & $\mathrm{M}_{40}$ & $\mathrm{M}_{10}$ \\
\hline
\end{tabular}




\begin{tabular}{|l|l|l|l|}
2 & 10,7 & 5,8 & 5,9 \\
\hline 3 & 12,8 & 6,9 & 7,0 \\
\hline 4 & 14,1 & 7,6 & 7,7 \\
\hline 5 & 15,0 & 8,1 & 8,3 \\
\hline
\end{tabular}

The calculated repeatability values are definitely higher than the values presented in the ISO 556 standard. Despite making the measurements in accordance with the standard, repeatable results fulfilling the repeatability criteria cannot be obtained.

Preparation of sample for the Micum test in accordance with the ISO 18283 standard consists in its appropriate composing according to mass fractions of a number of size fractions. With the increasing particle size the number of coke lumps, comprised by the sample intended for testing, decreases (even 5-10 times smaller for the foundry coke than in the case of coke of $+40 \mathrm{~mm}$ particles). Taking also into consideration a great qualitative diversification of individual $+100 \mathrm{~mm}$ coke lumps it should be stated that the representativeness of this fraction in the sample intended for testing drastically goes down. This results exactly in obtaining a poor repeatability of the $\mathrm{M}_{80}$ index.

\section{Conclusions}

- provisions of the ISO 18283 standard on the foundry coke of $+100 \mathrm{~mm}$ size sampling require taking a sample of very large mass $(\sim 1000 \mathrm{~kg})$ what implies unacceptable labour-consuming work at the plant

- $\quad$ ISO 556 does not give repeatability nor reproducibility for M80,

- for foundry coke $+100 \mathrm{~mm}$ grain size it is not possible to reach repeatability limit for M10,

- statistical analysis of test results shows that used testing methodologies does not give acceptable precision.

- $\quad$ there is need to prepare modified methodology of coke sampling and determination of Micum test of the foundry coke of $+100 \mathrm{~mm}$ and validate it.

\section{Evaluation of modified testing methodology}

Modification for new methodology had to provide for:

- $\quad$ to be based on ISO standards [1,4],

- routine work conditions at the industrial plant.

Taking this into account there was evaluated by IChPW simplified method [5] as follows:

Table 5

Description of IChPW simplified method

\begin{tabular}{|c|c|}
\hline Lot & railway shipment \\
\hline Sub-lot & single shift \\
\hline Sample size distribution & $+100 \mathrm{~mm}$ \\
\hline Sampling location & stopped conveyor belt \\
\hline Sampling area & full width, length of $\min .1 \mathrm{~m}$ \\
\hline Sampling frequency & min 5 times per shift \\
\hline Weight of the increment & $\min .36 \mathrm{~kg}$ \\
\hline Placing location of the increments & three containers \\
\hline $\begin{array}{l}\text { Method of averaging the general } \\
\text { sample }\end{array}$ & $\begin{array}{l}\text { randomly sampled pieces of coke are placed in consecutive containers, } \\
\text { means that the first portion to the container } 1 \text {, the second to the container } \\
2 \text {, the third to the container } 3 \text {, the fourth to the container } 1 \text {, the fifth to } \\
\text { the container } 2 \text {, etc. }\end{array}$ \\
\hline Weight of the general sample & $\min .180 \mathrm{~kg}$ \\
\hline Test sample & $\begin{array}{l}\text { a content of each container is a test sample, so that the mechanical strength } \\
\text { determination may be carried out } 3 \text { times. Should pay attention to the } \\
\text { careful placement of the portions to the container, so as not to cause an } \\
\text { uncontrolled change in the structure of the test coke }\end{array}$ \\
\hline Test sample mass & each container should contain min. $50 \pm 0,5 \mathrm{~kg}$ \\
\hline Tumbling method & analogously to ISO 556 \\
\hline
\end{tabular}

Strength indices are calculated analogously as in ISO 556:

Index $M_{80}(+100)$ calculated as a percentage according to the formula:

$M_{80}(+100)=\frac{m_{80}}{m} \times 100$

where: $m_{80}$ - coke mass remains on the control sieve with apertures diameter $80 \mathrm{~mm}$, in kilograms $m$ - mass of inserted coke into the drum, in kilograms 
Index $M_{40}(+100)$ calculated as a percentage according to the formula:

$M_{40}(+100)=\frac{m_{80}+m_{40}}{m} \times 100$

where: $m_{40}$ - coke mass remains on the control sieve with apertures diameter $40 \mathrm{~mm}$, in kilograms

Index $M_{10}(+100)$ calculated as a percentage according to the formula:

$M_{10}(+100)=\frac{m_{10}}{m} \times 100$

where: $m_{10}$ - fines mass remains under the control sieve with apertures diameter $10 \mathrm{~mm}$, in kilograms

The results of analysis of coke samples collected from the stopped conveyor belt are presented in Fig. 2 - 4.

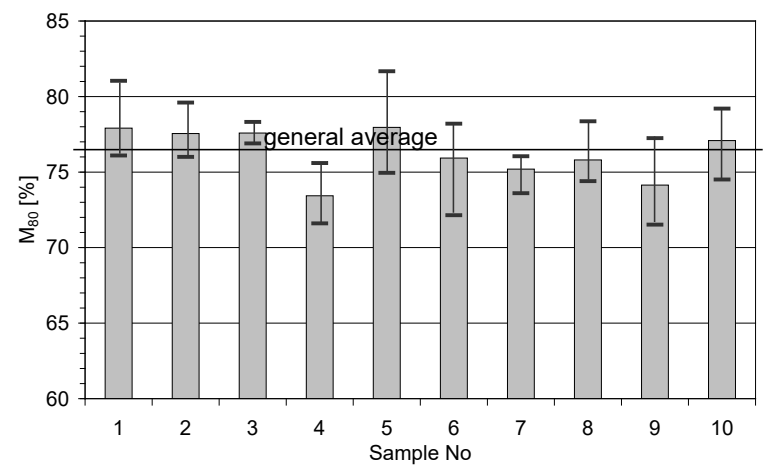

Fig. 2. Mean values of results in series with range and an overall mean value for $\mathrm{M}_{80}(+100)$ index

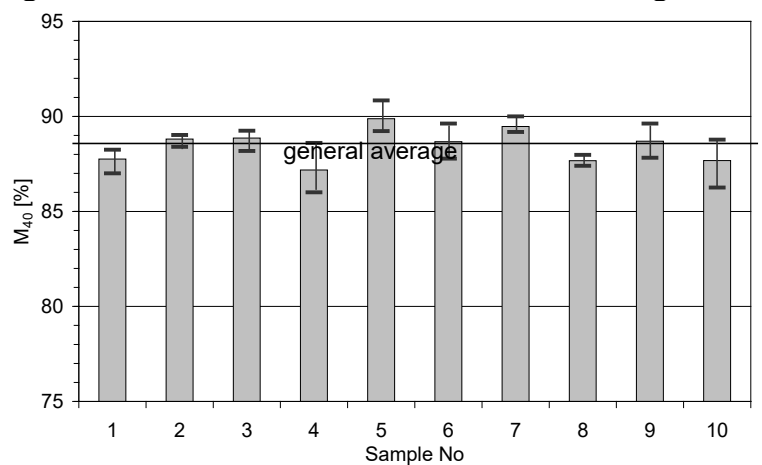

Fig. 3. Mean values of results in series with range and an overall mean value for $\mathrm{M}_{40}(+100)$ index

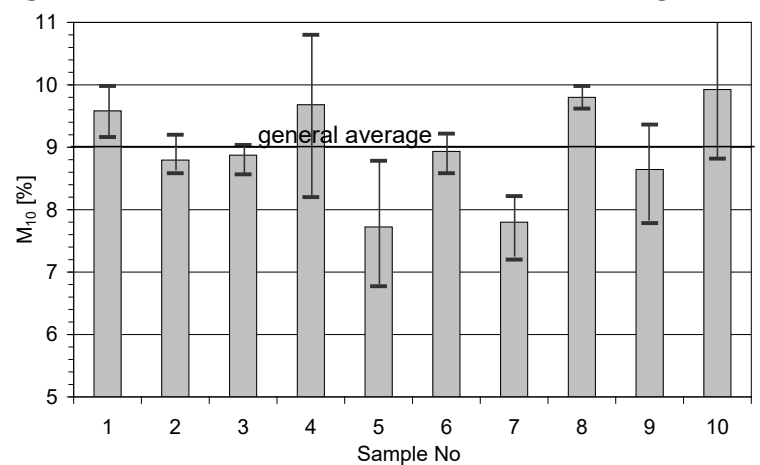

Fig. 4. Mean values of results in series with range and an overall mean value for $\mathrm{M}_{10}(+100)$ index

All mean values in individual series are close to the overall mean for $\mathrm{M}_{80}(+100), \mathrm{M}_{40}(+100)$ and $\mathrm{M}_{10}(+100)$ indices, which proves a high precision of strength indices measurements performance.

The evaluation of outliers was performed based on statistical methods provided in standard ISO 5725-2 [6]. The graphical Mandel method ( $\mathrm{h}$ and $\mathrm{k}$ statistics) and computational methods (Cochran and Grubbs) are described below, on the basis of which it is possible to identify outliers from all $\mathrm{M}_{80}(+100), \mathrm{M}_{40}(+100)$ and $\mathrm{M}_{10}(+100)$ results.

The graphical method is expressed by two Mandel statistics, $h$ and $k$. The $h_{m}$ statistics for $M_{80}(+100), M_{40}(+100)$ and $\mathrm{M}_{10}(+100)$ series were determined from the formula (6) presented in sub-clause 7.3.1.1 [6].

The $\mathrm{k}_{\mathrm{m}}$ statistics for $\mathrm{M}_{80}(+100), \mathrm{M}_{40}(+100)$ and $\mathrm{M}_{10}(+100)$ indices series were determined from the formula (7) presented in sub-clause 7.3.1.2 [6]. 
Mandel $\mathrm{h}$ index tests the intra-laboratory consistency of mean values, i.e. how much mean values in series deviate from the overall mean in terms of the value. The lower the differences, the closer to 0 will be values of Mandel h test.

Mandel $\mathrm{k}$ index presents the intra-laboratory consistency of standard deviation, i.e. how much mean values in series deviate from the overall mean in terms of the deviation. The lower the standard deviation, the closer to 0 will be values of Mandel $\mathrm{k}$ test.

The analysis of $\mathrm{h}$ and $\mathrm{k}$ statistics graphs informs that in the case of $\mathrm{M}_{80}(+100)$ and $\mathrm{M}_{40}(+100)$ index results series (Mandel h statistics) there are no uncertain values or outliers. In the case of $\mathrm{M}_{10}(+100)$ index an uncertain result for Mandel k statistic was obtained only for one series. A worse results repeatability and hence a higher standard deviation, affecting the value of Mandel $\mathrm{k}$ statistics, is the reason for such situation. Because of that, in the case of the other series there are no uncertain results or outliers, it is possible to consider that an uncertain result does not have a significant importance for the entire population and further calculations.

The proposed graphical method is used only for a preliminary visual assessment of outliers.

The decision on classifying a value as an outlier is made based on numerical Cochran and Grubbs tests.

To detect outliers in terms of standard deviation the Cochran statistics for the series was determined in accordance with the formula (8) presented in sub-clause 7.3.3.2 [6].

Based on Cochran test results it is possible to state that all standard deviation values are lower than the critical value for the significance level of $5 \%$, which shows that there are no outliers.

Another numerical method - the Grubbs test - enables evaluation of mean values consistency. $G_{p}$ (for the highest value) and $\mathrm{G}_{1}$ (for the lowest value) statistics were determined according to formula (9) and (10) presented in sub-clause 7.3.4.1 [6].

Based on the Grubbs test results it is possible to state that all mean values are lower than the critical value for the significance level of $5 \%$, which shows that there are no outliers.

Verification of the assumption about normality of the obtained data mean values is carried out using the Shapiro-Wilk test. The value of test probability $\mathrm{p}$ is the result of test. Results of measurements for individual $\mathrm{M}_{80}(+100), \mathrm{M}_{40}(+100)$ and $\mathrm{M}_{10}(+100)$ indices are subject to normal distribution, if the calculated value of test probability $p$ is higher than the assumed significance level for the test $(p=0.05)$.

Based on the Shapiro-Wilk test and normality graphs the mean values of $\mathrm{M}_{80}(+100), \mathrm{M}_{40}(+100)$ and $\mathrm{M}_{10}(+100)$ indices feature a normal distribution.

Precision defines the degree of consistency between independent results obtained in specified conditions. Precision components comprise repeatability and indirect precision (intra-laboratory reproducibility).

The repeatability describes the consistency degree of consecutive results obtained in the same measurement conditions. Standard deviation of repeatability $\mathrm{s}_{\mathrm{r}}$, repeatability limit $\mathrm{r}$ and variation coefficient $\% \mathrm{~s}_{\mathrm{r}}$ were determined to specify the repeatability. The standard deviation of repeatability is determined on the basis of independent repetitions of the same object measurements in conditions of repeatability. The deviation was determined according to the formula (20) presented in sub-clause 7.4.5.1 [6].

The repeatability limit is the value, which with $95 \%$ probability cannot be exceeded by the absolute difference between two parallel measurement results in consecutive measurements performed in conditions of repeatability. It is calculated based on the formula:

$\mathrm{r}=\mathrm{f}(\mathrm{n}) \cdot \mathrm{s}_{\mathrm{r}}$

where:

$\mathrm{f}(\mathrm{n})$ - Pearson coefficient, depending on the number of repetitions $\mathrm{n}$ (from tables),

$\mathrm{S}_{\mathrm{r}}$ - standard deviation of repeatability.

Variation coefficient $\left(\% \mathrm{~s}_{\mathrm{r}}\right)$ was calculated acc. to the formula:

$\% \mathrm{~s}_{\mathrm{r}}=\frac{\mathrm{s}_{\mathrm{r}}}{\overline{\overline{\mathrm{X}}}} \cdot 100$

where:

$\mathrm{s}_{\mathrm{r}}-$ standard deviation of repeatability.

$\overline{\bar{X}}$ - overall mean of results.

Table 6 presents the results of calculations.

Table 6

Standard deviation of repeatability $\left(\mathrm{s}_{\mathrm{r}}\right)$, repeatability limit $(\mathrm{r})$, variation coefficient $\left(\% \mathrm{~s}_{\mathrm{r}}\right)$ for $\mathrm{M}_{80}(+100), \mathrm{M}_{40}(+100)$ i $\mathrm{M}_{10}(+100)$ indices

\begin{tabular}{|c|c|c|c|}
\cline { 2 - 4 } \multicolumn{1}{c|}{} & $\mathbf{M}_{\mathbf{8 0}}(+\mathbf{1 0 0})$ & $\mathbf{M}_{\mathbf{4 0}}(+\mathbf{1 0 0})$ & $\mathbf{M}_{\mathbf{1 0}}(+\mathbf{1 0 0})$ \\
\hline $\mathbf{s} \mathbf{r}$ & 2,43 & 0,83 & 0,75 \\
\hline $\mathbf{r}$ & 8,05 & 2,74 & 2,49 \\
\hline
\end{tabular}




\begin{tabular}{|l|l|l|l|}
\hline $\mathbf{\%} \mathbf{S}_{\mathbf{r}}$ & 3,19 & 0,94 & 8,36 \\
\hline
\end{tabular}

The indirect precision presents the consistency degree of measurement results for the same measured value, performed in changed measurement conditions. Standard deviation of indirect repeatability $\mathrm{S}_{\mathrm{R}}$, indirect repeatability limit $\mathrm{R}$ and variation coefficient $\% \mathrm{~S}_{\mathrm{R}}$ were determined to specify the indirect precision. The standard deviation of indirect precision (intra-laboratory reproducibility) is determined based on results of independent repetitions of the same object measurements in conditions of reproducibility in one laboratory. The deviation was determined according to the formula (24) presented in sub-clause 7.4.5.5 [6].

The indirect precision limit is the value, which with $95 \%$ probability cannot be exceeded by the absolute difference between two parallel measurement results in consecutive measurements performed in conditions of repeatability. The indirect precision limit $(\mathrm{R})$ has been calculated acc. to the formula:

$\mathrm{R}=\mathrm{f}(\mathrm{n}) \cdot \mathrm{S}_{\mathrm{R}}$

$\mathrm{f}(\mathrm{n})$ - Pearson coefficient, depending on the number of repetitions $\mathrm{n}$ (from tables),

$\mathrm{s}_{\mathrm{r}}-$ standard deviation of intra-laboratory reproducibility.

Variation coefficient $\left(\% \mathrm{~S}_{R}\right)$ was calculated acc. to the formula:

$\% \mathrm{~s}_{\mathrm{R}}=\frac{\mathrm{s}_{\mathrm{R}}}{\overline{\overline{\mathrm{X}}}} \cdot 100 \%$

$\mathrm{S}_{\mathrm{R}}-$ standard deviation of intra-laboratory reproducibility.

$\overline{\bar{X}}$ - overall mean of results.

Table 7 presents the results of calculations.

Table 7.

Standard deviation of indirect repeatability $\mathrm{S}_{\mathrm{R}}$, indirect repeatability limit $\mathrm{R}$ and variation coefficient $\% \mathrm{~S}_{\mathrm{R}}$ for $\mathrm{M}_{80}(+100), \mathrm{M}_{40}(+100)$ i $\mathrm{M}_{10}(+100)$ indices

\begin{tabular}{|c|c|c|c|}
\cline { 2 - 4 } \multicolumn{1}{c|}{} & $\mathbf{M}_{\mathbf{8 0}}(+\mathbf{1 0 0})$ & $\mathbf{M}_{\mathbf{4 0}}(+\mathbf{1 0 0})$ & $\mathbf{M}_{\mathbf{1 0}}(+\mathbf{1 0 0})$ \\
\hline $\mathbf{S R}$ & 2,56 & 1,10 & 1,00 \\
\hline $\mathbf{R}$ & 8,48 & 3,64 & 3,29 \\
\hline $\mathbf{\%} \mathbf{S}_{\mathbf{R}}$ & 3,36 & 1,24 & 11,08 \\
\hline
\end{tabular}

The standard uncertainty was determined based on statistical analysis of results of measurement series of $\mathrm{M}_{80}(+100), \mathrm{M}_{40}(+100)$ and $\mathrm{M}_{10}(+100)$ index. The uncertainty value is determined as described in point 4.2.1. formula (3) [7].:

The extended uncertainty of measurement is determined from the formula [7]:

$\mathrm{U}_{\mathrm{x}}=\mathrm{t}(1-1 / 2 \alpha, \mathrm{m}-1) \cdot \mathrm{u}_{\mathrm{x}}$

where:

$\mathrm{u}_{\mathrm{x}}-$ standard uncertainty of measurement,

$t(1-1 / 2 \alpha, m-1)$ - coefficient determined from t-Student distribution on the significance level $(1-1 / 2 \alpha)$ and of $(\mathrm{m}-1)$ degrees of freedom (from tables).

Mean values together with extended uncertainties for $\mathrm{M}_{80}(+100), \mathrm{M}_{40}(+100)$ and $\mathrm{M}_{10}(+100)$ indices are presented in Table 8 .

Table 8 .

Mean values together with extended uncertainties

\begin{tabular}{|c|c|c|c|}
\cline { 2 - 4 } \multicolumn{1}{c|}{} & $\mathbf{M}_{\mathbf{8 0}}(+\mathbf{1 0 0})$ & $\mathbf{M}_{\mathbf{4 0}}(+\mathbf{1 0 0})$ & $\mathbf{M}_{\mathbf{1 0}}(+\mathbf{1 0 0})$ \\
\hline$\overline{\overline{\mathrm{X}}} \pm \mathrm{U}_{\mathrm{x}}$ & $76,26 \pm 2,99$ & $88,46 \pm 0,99$ & $8,98 \pm 0,83$ \\
\hline
\end{tabular}

Figures $5-7$ present mean values in individual series, overall mean values together with extended uncertainties for $\mathrm{M}_{80}(+100), \mathrm{M}_{40}(+100)$ and $\mathrm{M}_{10}(+100)$ indices. 


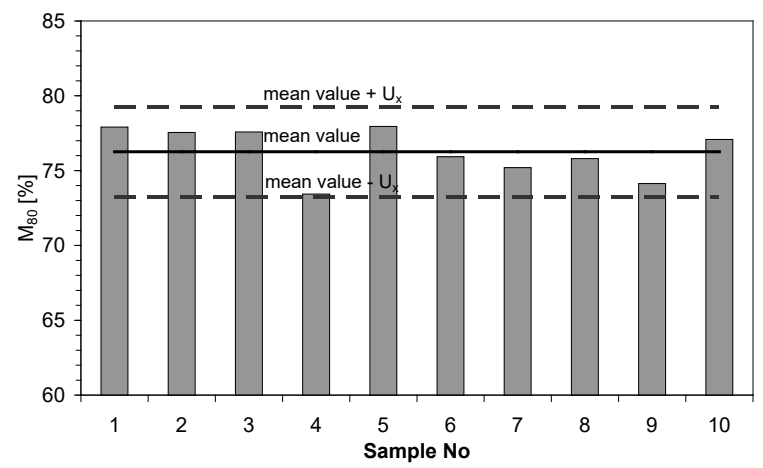

Fig. 5. Mean values in series, overall mean values with extended uncertainties for $\mathrm{M}_{80}(+100)$ index

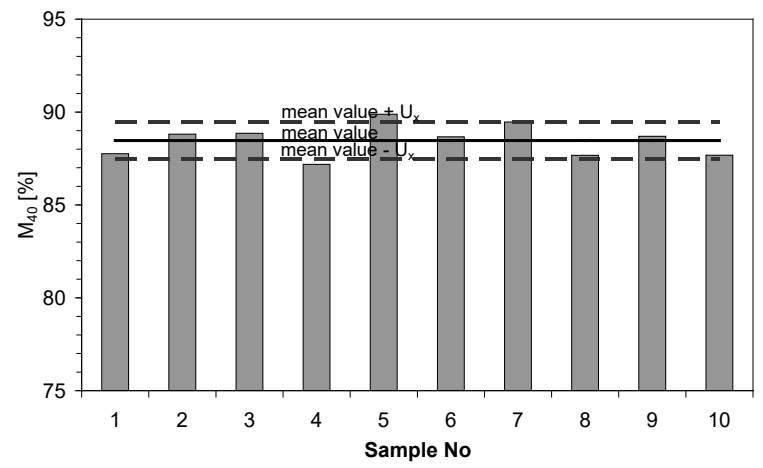

Fig. 6. Mean values in series, overall mean values with extended uncertainties for $\mathrm{M}_{40}(+100)$ index

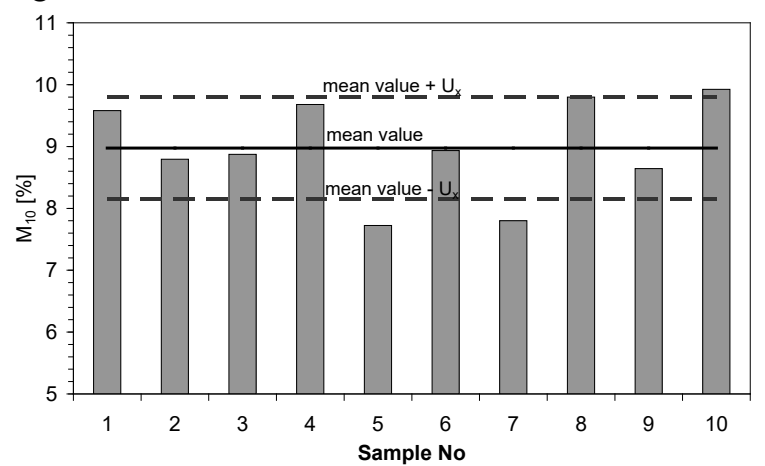

Fig. 7. Mean values in series, overall mean values with extended uncertainties for $\mathrm{M}_{10}(+100)$ index

In the case of $\mathrm{M}_{80}(+100)$ index all mean values in series fall within the range: overall mean \pm extended uncertainty of the measurement. In the case of $\mathrm{M}_{40}(+100)$ index one value slightly exceeds the discussed range, while in the case of $\mathrm{M}_{10}(+100)$ index three mean values exceed the range: overall mean \pm extended uncertainty of the measurement. The uncertainty of measurement is a mean of all uncertainties of measurements for individual series and therefore takes into account all ranges between individual results.

Analysing the estimated values of extended uncertainties for individual indices it is possible to notice that the $\mathrm{M}_{40}(+100)$ index tests were performed with the highest accuracy, while $\mathrm{M}_{10}(+100)$ tests with the lowest accuracy. It also may be noticed on the basis of standard deviation of mean values in individual series of $\mathrm{M}_{80}(+100)$, $\mathrm{M}_{40}(+100)$ and $\mathrm{M}_{10}(+100)$ indices from the overall mean and variation coefficient $\mathrm{S}_{\mathrm{r}}$ and $\mathrm{S}_{\mathrm{R}}$. They are the highest among appropriate values for the other.

The repeatability limit is determined based on formula (11). This formula considers the Pearson coefficient, depending on the number of repetitions $n$ (from tables) and the standard deviation of repeatability $\mathrm{s}_{\mathrm{r}}$.

In the case of series of measurements for 2 repetitions the $\mathrm{s}_{\mathrm{r}}$ deviation was determined acc. to the formula:

$\mathrm{s}_{\mathrm{r}}=\sqrt{\frac{\sum_{\mathrm{i}=1}^{\mathrm{m}}\left(\mathrm{x}_{1}-\mathrm{x}_{2}\right)^{2}}{2 \mathrm{~m}}}$

To calculate repeatability limits three combinations of result pairs were selected from among previously made three repetitions separately for each series. This way 30 pairs of results were obtained, based on which the repeatability limits were determined. 
Calculated values of repeatability limits are presented in Table 9.

Table 9.

Repeatability limits vs. the number of repetitions

\begin{tabular}{|c|c|c|c|}
\hline Number of repetitions & $\mathbf{M}_{\mathbf{8 0}}(\mathbf{+} \mathbf{1 0 0})$ & $\left.\mathbf{M}_{\mathbf{4 0}} \mathbf{( + 1 0 0}\right)$ & $\mathbf{M}_{\mathbf{1 0}}(+\mathbf{1 0 0})$ \\
\hline 2 & 6,7 & 2,3 & 2,1 \\
\hline 3 & 8,1 & 2,7 & 2,5 \\
\hline
\end{tabular}

\section{Summary}

1. ISO standards for sampling and testing foundry coke $+100 \mathrm{~mm}$ gives results inadequate to applied labour.

2. ISO 556 does not give information on repeatability for $\mathrm{M}_{80}$ index and for $\mathrm{M}_{10}$ it is almost impossible to reach it.

3. IChPW has prepared simplified method for foundry coke of $+100 \mathrm{~mm}$ sampling and determination of coke strength indices (technical procedure No. Q/LP/61/A - "Determination of mechanical strength for foundry coke of $+100 \mathrm{~mm}$ grain").

4. There were evaluated repeatability limits for strength indices.

5. Results obtained with use of the procedure have following uncertainties:
a. for $\mathrm{M}_{80}(+100)-\mathrm{U}_{\mathrm{x}}=3,0 \%$
b. for $\mathrm{M}_{40}(+100)-\mathrm{U}_{\mathrm{x}}=1,0 \%$
c. $\quad$ for $\mathrm{M}_{10}(+100)-\mathrm{U}_{\mathrm{x}}=0,8 \%$

6. The developed procedure is simple and practicable in industrial plant conditions and can be implemented in any plant which want to reliably asses quality coke foundry coke.

\section{References}

1. ISO 556:1980 Coke (greater than $20 \mathrm{~mm}$ in size) - Determination of mechanical strength, retrieved from https://www.iso.org/standard/4644.html

2. Loison, R.,Foch, P., Boyer, A. (1989) Coke Quality and Production, Edited by Butterworth, London 3. E.R.Daw, S. Hanson, J.W. Patrick (2001) Structural Features Influencing Coke Degradation, Proceedings of ACS Carbon Conference, Lexington, KY, July 14-19, 2001, Session 16, 16.4

4. ISO 18283 Hard coal and coke - Manual sampling, retrieved from https://www.iso.org/standard/31776.html 5. IChPW Technical procedure Q/PL/ 61 /A: 2012 Determination of the mechanical strength of foundry coke $+100 \mathrm{~mm}$ grain size (unpublished)

6. ISO 5725-2 Accuracy (trueness and precision) of measurement methods and results - Part 2: Basic method for the determination of repeatability and reproducibility of a standard measurement method, retrieved from https://www.iso.org/standard/69419.html

7. ISO/IEC Guide 98-3:2008 - Uncertainty of measurement - Part 3, Guide to the expression of uncertainty in measurement (GUM:1995), retrieved from https://www.iso.org/standard/50461.html 
Fig. 1. Results of $\mathrm{M}_{80}, \mathrm{M}_{40}$ and $\mathrm{M}_{10}$ index

Fig. 2. Mean values of results in series with range and an overall mean value for $\mathrm{M}_{80}(+100)$ index

Fig. 3. Mean values of results in series with range and an overall mean value for $M_{40}(+100)$ index

Fig. 4. Mean values of results in series with range and an overall mean value for $\mathrm{M}_{10}(+100)$ index

Fig. 5. Mean values in series, overall mean values with extended uncertainties for $\mathrm{M}_{80}(+100)$ index Fig. 6. Mean values in series, overall mean values with extended uncertainties for $M_{40}(+100)$ index

Fig. 7. Mean values in series, overall mean values with extended uncertainties for $M_{10}(+100)$ index 
Table 1

Comparison of the applied methodologies of foundry coke $+100 \mathrm{~mm}$ sampling

Table 2 .

Mean value $\bar{x}$, range, repeatability deviation $s_{r}$ and repeatability limit $r$

Table 3

Repeatability limit $r$ versus the number of repetitions

Table 4

Repeatability for $\mathrm{M}_{80}, \mathrm{M}_{40}$ and $\mathrm{M}_{10}$ versus the number of repetitions

Table 5

Description of IChPW simplified method

Table 6

Standard deviation of repeatability $\left(\mathrm{s}_{\mathrm{r}}\right)$, repeatability limit $(\mathrm{r})$, variation coefficient $\left(\% \mathrm{~s}_{\mathrm{r}}\right)$ for $\mathrm{M}_{80}(+100)$,

$\mathrm{M}_{40}(+100)$ i $\mathrm{M}_{10}(+100)$ indices

Table 7.

Standard deviation of indirect repeatability $\mathrm{s}_{\mathrm{R}}$, indirect repeatability limit $\mathrm{R}$ and variation coefficient $\% \mathrm{~s}_{\mathrm{R}}$ for $\mathrm{M}_{80}(+100), \mathrm{M}_{40}(+100)$ i $\mathrm{M}_{10}(+100)$ indices

Table 8 .

Mean values together with extended uncertainties

Table 9.

Repeatability limits vs. the number of repetitions 
Figures

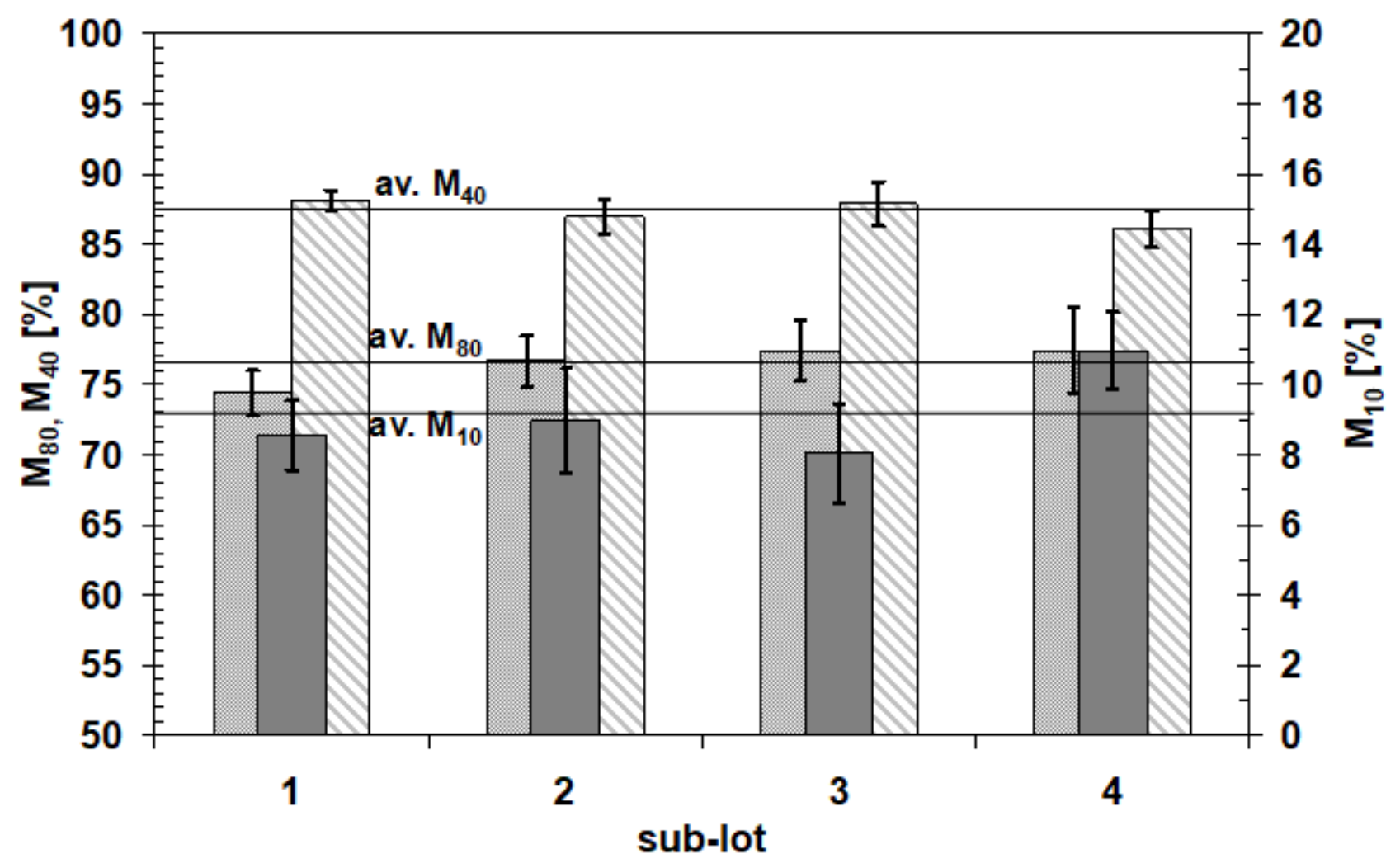

Figure 1

Results of M80, M40 and M10 index

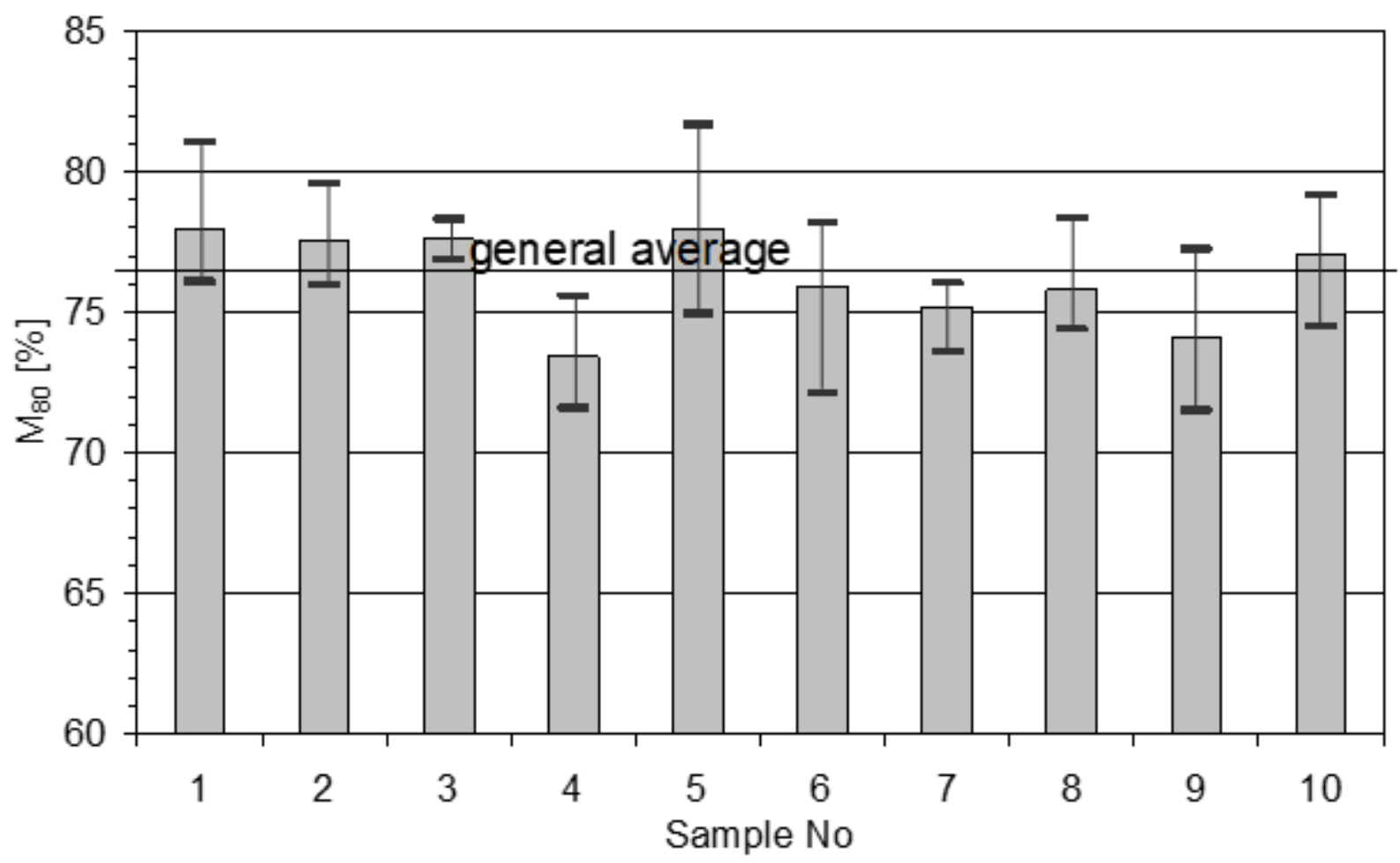


Figure 2

Mean values of results in series with range and an overall mean value for M80(+100) index

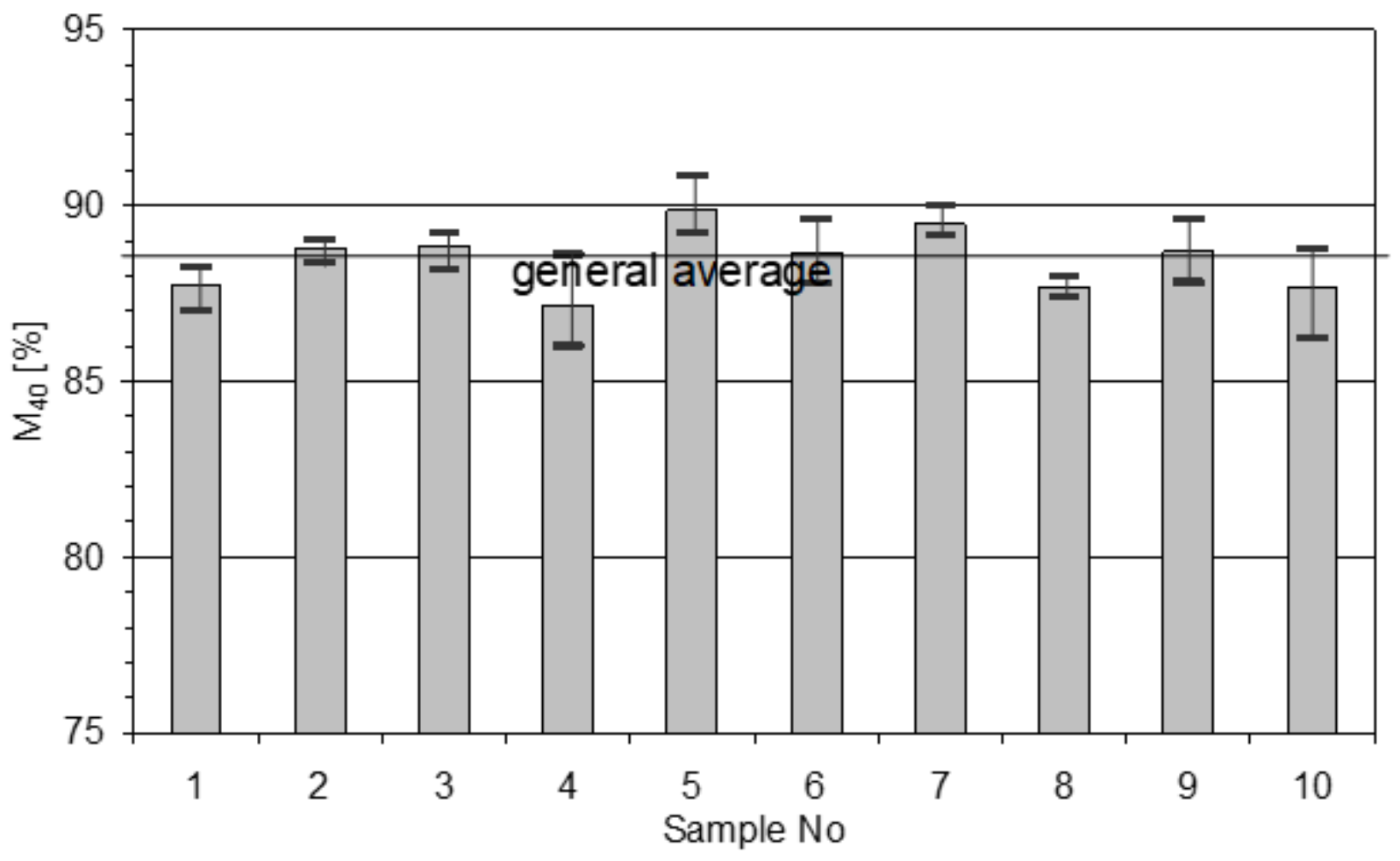

Figure 3

Mean values of results in series with range and an overall mean value for M40(+100) index

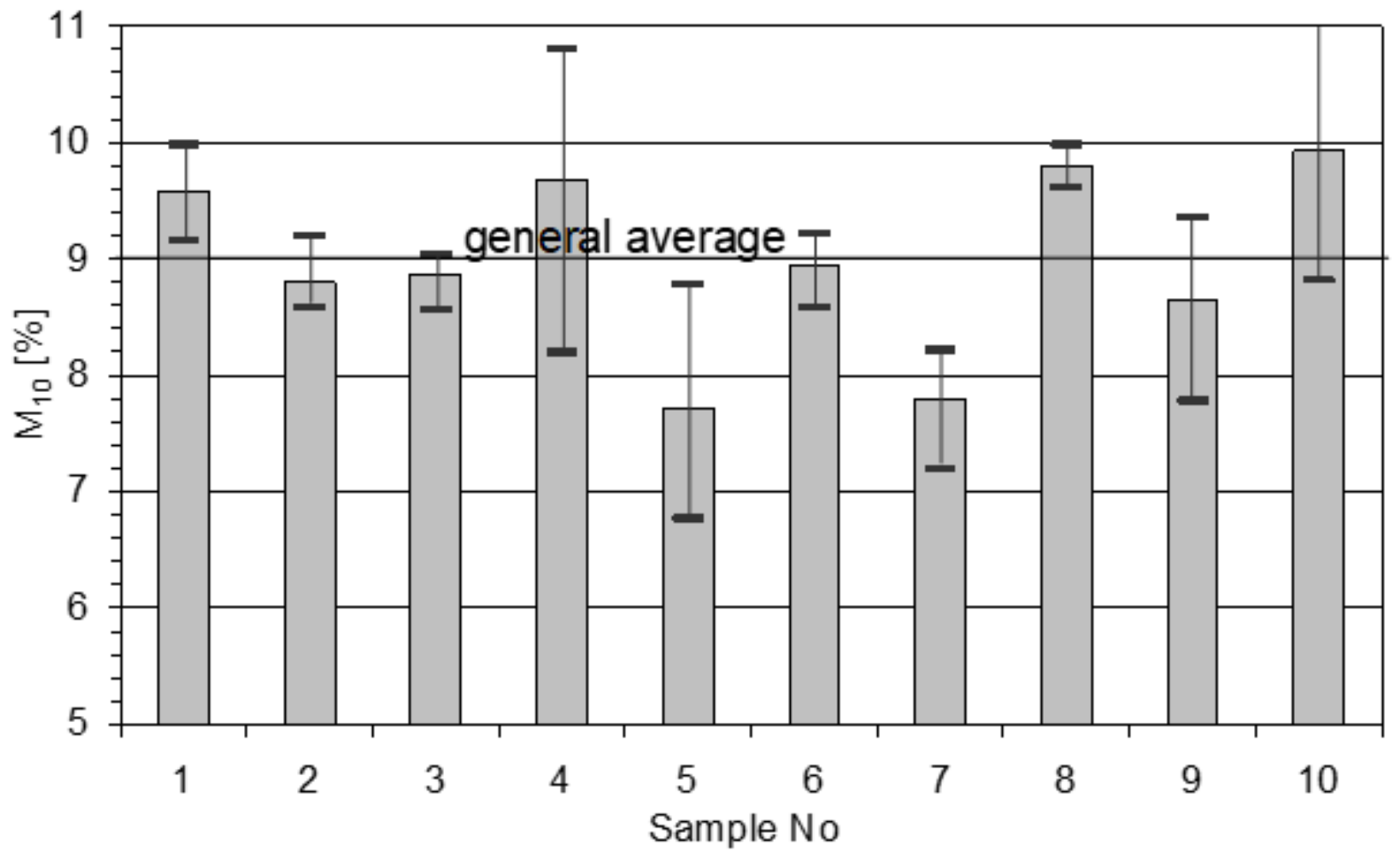

Figure 4 
Mean values of results in series with range and an overall mean value for M10(+100) index

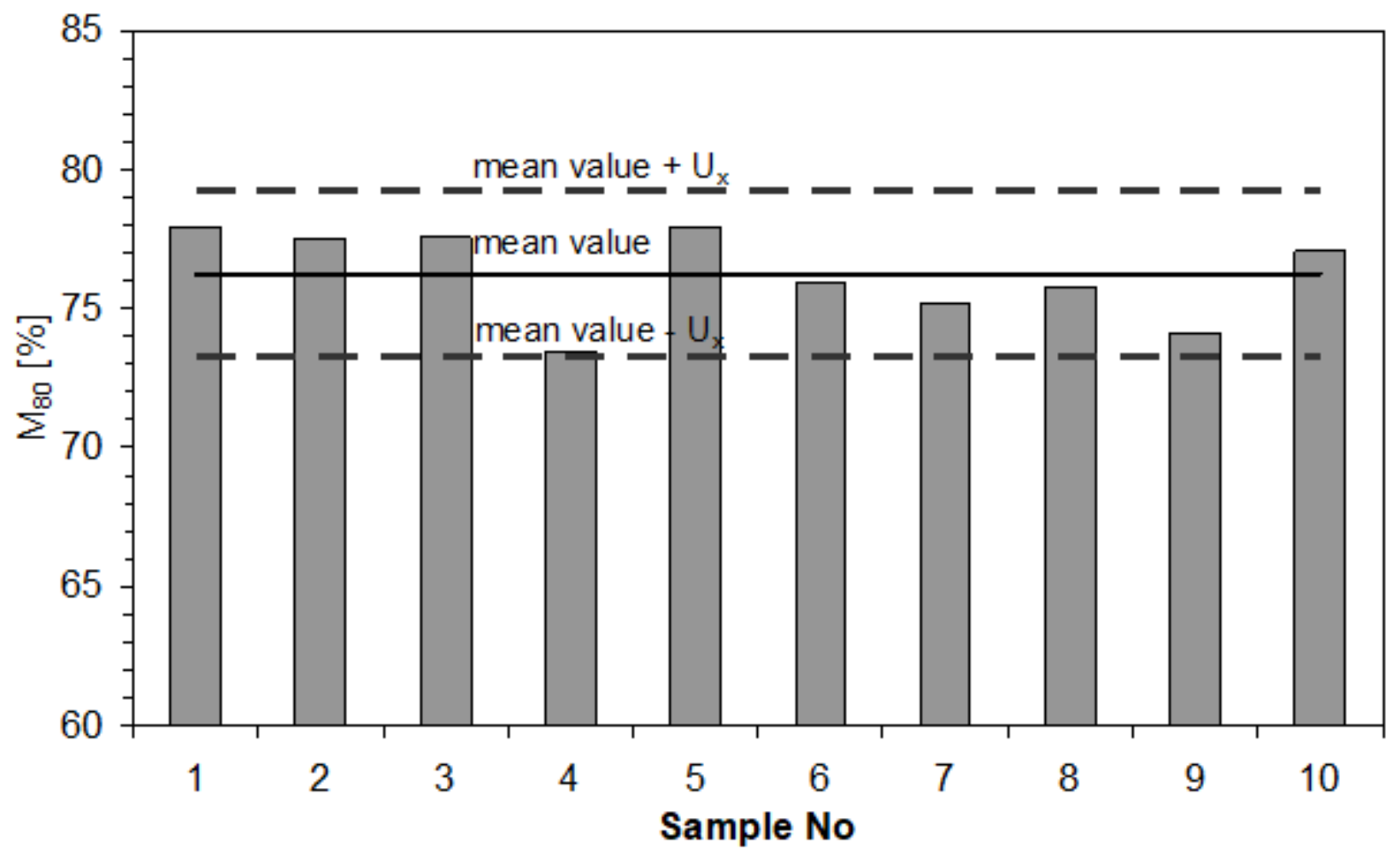

Figure 5

Mean values in series, overall mean values with extended uncertainties for M80(+100) index

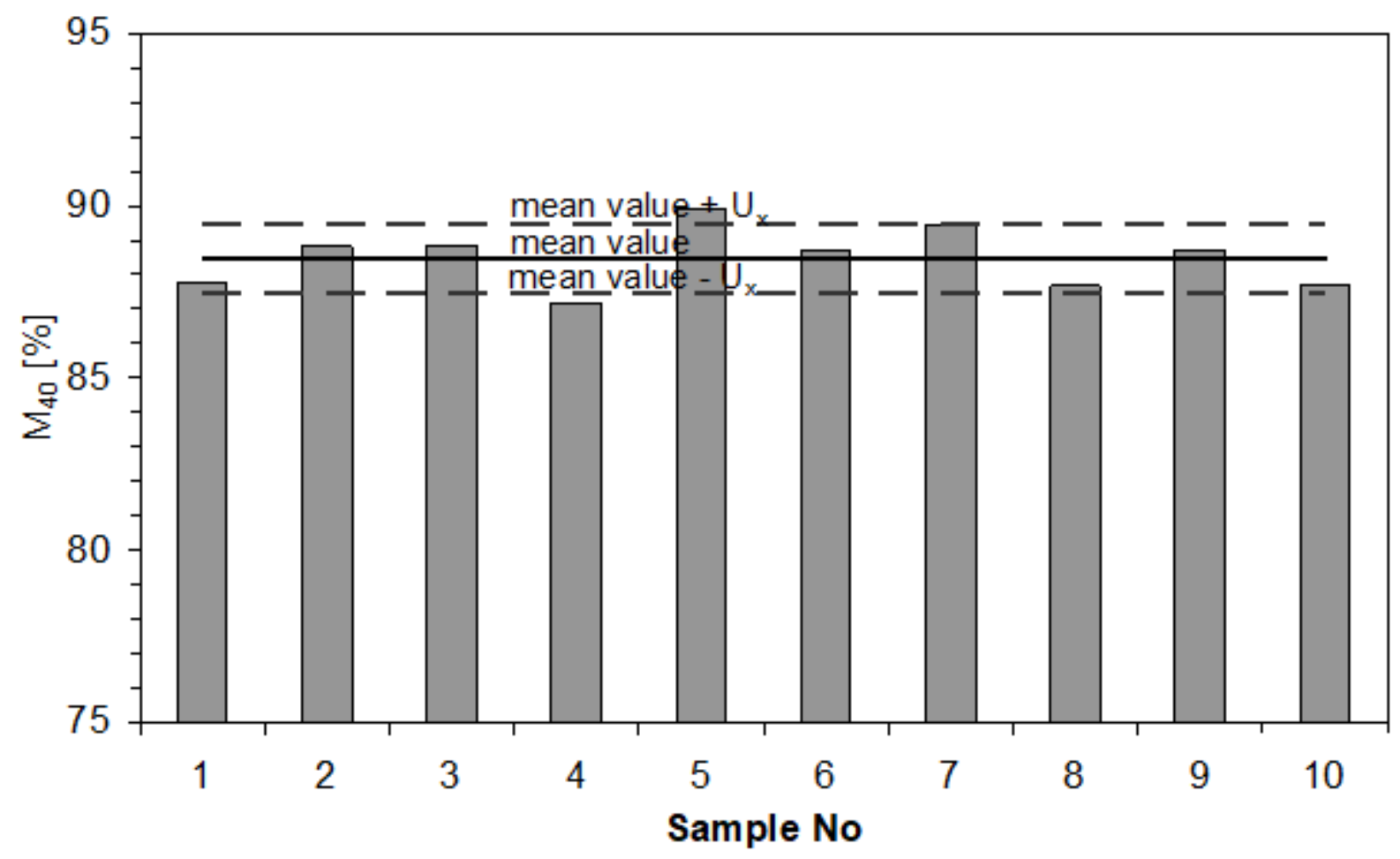

Figure 6 
Mean values in series, overall mean values with extended uncertainties for M40 $(+100)$ index

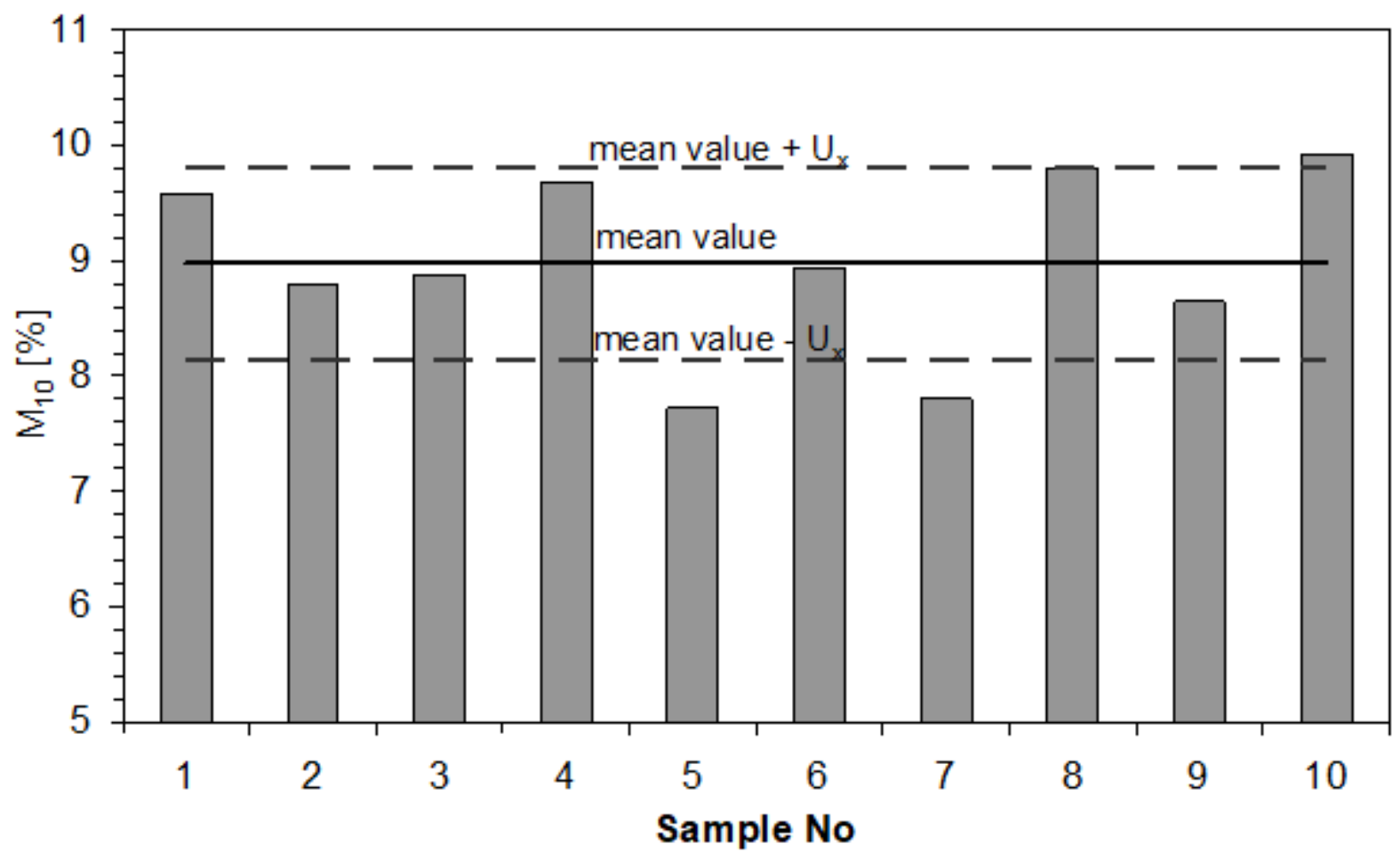

Figure 7

Mean values in series, overall mean values with extended uncertainties for M10(+100) index 